Filol. linguíst. port., São Paulo, 15(2), p. 369-383, Jan./Jun. 2013.

DOI: http://dx.doi.org/10.11606/issn.2176-9419.v15i2p369-383.

\title{
Flutuação na segmentação de palavras: relações entre constituintes prosódicos e convenções ortográficas na escrita infantil
}

Fluctuation in words segmentation: relationships of prosodic constituents to orthographic conventions in children writing

\author{
Lourenço Chacon \\ Universidade Estadual Paulista, Brasil \\ lourencochacon@yahoo.com.br
}

Resumo: Neste artigo, foram analisadas situações em que (a) uma mesma estrutura vocabular apresentava-se de duas diferentes maneiras em um mesmo texto ou (b) apresentava-se com rasuras. Essas flutuações de estrutura foram extraídas de textos escritos por crianças que, à época da coleta, frequentavam a segunda série do ensino fundamental. Quanto aos resultados, verificou-se que: (1) mais de um constituinte prosódico mostrouse na base das flutuações de estrutura vocabular; e (2) pelo menos um dos limites das palavras ortográficas foi mantido nas estruturas flutuantes. Esses resultados sugerem a recuperação que os escreventes fazem de informações a que têm acesso pela sua inserção em (1) práticas de oralidade e em (2) práticas de letramento.

Palavras-chave: aquisição da escrita, ortografia, prosódia, oralidade, letramento

\begin{abstract}
In this paper, we analyzed situations where (a) one vocabular structure showed in two different ways in the same text or (b) had erasures. These structures fluctuations were extracted from texts written by children that, when the registers were done, were second graders of elementary school. Concerning the results, we verified: (1) that more than one prosodic constituent showed in the basis of fluctuation of vocabulary structures; and (2) that
\end{abstract}


at least one of the limits of orthographic words was maintained in fluctuation structures. These results point to the recuperation done by writers with information they have access due to their insertion in (1) oral practices and (2) literacy practices.

Keywords: writing acquisition, orthography, prosody, orality, literacy.

\section{Introdução}

Leitura obrigatória para quem deseja pesquisar segmentações nãoconvencionais em textos infantis ${ }^{1}$ é o trabalho $A$ relevância dos critérios prosódicos e semânticos na elaboração de hipóteses sobre segmentação na escrita infantil (Abaurre, 1991). Com efeito, nesse original trabalho, Abaurre levanta um sem número de questões envolvidas na maneira como os espaços em branco delimitam unidades gráficas em textos infantis.

Dentre essas questões, uma delas chama-nos particularmente a atenção:

(...) às vezes em um mesmo texto, critérios de segmentação aparentemente conflitantes são freqüentemente usados por uma mesma criança, o que parece indicar que as crianças podem explorar critérios conflitantes de forma mais ou menos simultânea, na tentativa de atribuírem sentido ao sistema convencional da linguagem escrita. (Abaurre, 1991: 205).

Justamente conflitos de crianças em relação à segmentação de palavras é que destacaremos neste estudo - mais especificamente conflitos que envolvem relações entre convenções ortográficas e constituintes prosódicos, tais como aqueles propostos por Nespor \& Vogel (1986).

Temos explorado essas relações em trabalhos anteriores (por exemplo: Chacon, 2004, 2005 e 2006), nos quais, além de contribuições de Abaurre, estão também sempre presentes contribuições fundamentais de Tfouni e de Corrêa.

De Tfouni, temos reforçado a idéia de que

não existe, nas sociedades modernas, o letramento 'grau zero', que equivaleria ao 'iletramento'. Do ponto de vista do processo sócio-histórico, o

\footnotetext{
${ }^{1} \mathrm{E}$ mesmo em textos de adultos em início de alfabetização, como o fizeram, por exemplo, Tenani (2004) e Ferreira (2009).
} 
que existe de fato nas sociedades industriais modernas são 'graus de letramento', sem que com isso se pressuponha sua inexistência. (Tfouni, 2000: 23)

Assim, em sociedades como a nossa, sobretudo em médios e grandes centros urbanos, mesmo sujeitos não-alfabetizados estão de alguma maneira inseridos em práticas de linguagem que supõem seu confronto com informações linguísticas difundidas por meio de caracteres ortográficos. Incluem-se, obviamente, nesse grupo de sujeitos, crianças que ainda não ingressaram no ensino fundamental. Afinal, embora ao ingressarem nesse ciclo de sua escolarização nem sempre as crianças dominem formalmente os critérios de organização da escrita alfabética, mesmo assim, em alguma medida, ancoramse em vivências que trazem de sua história de letramento para produzirem seus enunciados escritos iniciais, independentemente de serem, ou não, alfabetizadas e, ainda, de quanto o seriam. Em outras palavras, Existem bons motivos para supor que a representação de escrita que o indivíduo já traz para a escola seja mais complexa, por mais limitado que tenha sido o seu contato com a escrita e seus usos. (Abaurre, 1987: 193 - destaque da autora). A segmentação (de palavras, de partes de textos) certamente faz parte de vivências de letramento, já que, em qualquer lugar de um centro urbano, as crianças estão em contato com placas, rótulos, embalagens, jornais, revistas etc., nos quais sequências de grafemas separadas por espaços em branco são muitíssimo frequentes. Consequentemente, não será no ensino fundamental (ou mesmo na educação infantil) que as crianças entrarão em contato, pela primeira vez, com blocos de letras separados por espaços em branco!

Mas não só em práticas de letramento essas crianças estão inseridas, já que, se não tiverem condição patológica que limite (muito) suas possibilidades de fala e de audição, certamente desde o seu nascimento estarão às voltas com informações linguísticas que circulam em práticas de oralidade. Essa inserção também determinará sua produção escrita, como o demonstram fragmentos de enunciados escritos extraídos de corpus de nossa pesquisa, como vaiticata (vai te catar), iviu (e viu), noscive (nós se vê) - que remetem ao modo como essas expressões são comumente faladas em estilos de fala mais informais do interior paulista. Assim, também no modo como as informações linguísticas circulam em práticas de oralidade as crianças se ancoram ao produzirem seus enunciados escritos iniciais.

Deduz-se, pois, que os enunciados escritos produzidos pelas crianças em início de seu processo de escolarização são efeito de uma conjunção entre: (1) informações linguísticas que circulam em práticas de letramento, nas quais se dá o confronto da criança com informações linguísticas difundidas por meio de propriedades gráfico-visuais; e (2) informações linguísticas que circulam em 
práticas de oralidade, nas quais se dá o confronto da criança com informações linguísticas difundidas por meio de propriedades acústico-auditivas.

Essa conjunção, na escrita infantil, remete, na verdade, à própria natureza do produto escrito - e a caracterização desse produto, por sua vez, nos leva às contribuições de Corrêa (2004) há pouco mencionadas. Como bem o detectou esse autor, os enunciados escritos - e não só os infantis - ancoram-se, simultaneamente, em elementos com os quais os sujeitos escreventes tiveram vivências nas práticas de letramento e de oralidade que possibilitaram sua constituição como escreventes. Consequentemente, para o estudioso da escrita, (...) é sempre o produto do trânsito entre práticas sociais orais/faladas e letradas/escritas que (...) chega como material de análise do modo de enunciação falado e do modo de enunciação escrito (Corrêa, 2001: 142, grifo nosso). Decorre da constatação dessa heterogeneidade forte motivação para o nosso interesse pelas relações entre convenções ortográficas e constituintes prosódicos. É que essas relações, em grande medida, indiciam a recuperação que os sujeitos escreventes fazem de suas vivências com enunciados falados (nos quais aspectos prosódicos contribuem enormemente para sua estruturação) e com enunciados escritos (nos quais, convencionalmente, unidades morfológicas como palavras têm realce, já que se separam umas das outras por meio de espaços em branco).

O estudo dessa relação possibilita, portanto, levantar indícios sobre a constituição da criança como sujeito escrevente e, logo, sobre sua ancoragem, frequentemente cheia de conflitos - sobretudo na produção de seus primeiros textos -, em elementos linguísticos (de base semiótica acústico-auditiva e gráfico-visual) que circulam, respectivamente, em práticas de oralidade e em práticas de letramento.

Uma marca bastante característica desses conflitos são as flutuações na escrita infantil que ocorrem em um mesmo texto - e aqui retomamos a proposta deste estudo, de abordá-las em relação à segmentação de palavras. Como se verá adiante, em alguns casos, trata-se de uma dupla flutuação, a saber, não só aquela verificada entre pelo menos duas ocorrências distintas de segmentação não-convencional, como também aquela verificada numa mesma ocorrência, como fruto de um processo de apagamento que deixa marcas na estrutura escrita.

Os dados que analisaremos foram extraídos de textos de crianças que, à época de sua produção, frequentavam a segunda série do primeiro ciclo do ensino fundamental em uma escola municipal de São José do Rio Preto 
$(\mathrm{SP})^{2}$. Fazem parte de um banco de dados (organizados transversal e longitudinalmente) sobre o processo comumente chamado de aquisição da escrita, que visa subsidiar o desenvolvimento de trabalhos acadêmicos do Grupo de Pesquisa (CNPq) Estudos sobre a linguagem (GPEL/CNPq), que coordenamos ${ }^{3}$.

A primeira e a segunda ocorrência que analisaremos foram extraídas, cada uma, de um texto diferente, produzido por duas diferentes crianças. Em sua produção, no dia 07 de março de 2002 :

(...) o pesquisador distribuiu entre as crianças uma cópia de uma história em quadrinhos e solicitou, inicialmente, que as crianças observassem a história que se passava nestes quadrinhos. Em seguida, pediu a algumas das crianças que contassem, oralmente, a história dos quadrinhos; após essa atividade oral, o pesquisador solicitou que as crianças iniciassem a produção do texto. Nesse momento, o pesquisador sugeriu às crianças que não apenas contassem a história que se passava nos quadrinhos mas, também, que acrescentassem, por exemplo, o que poderia ter ocorrido após o término do último quadrinho. (Capristano, 2007: 176).

Já a terceira ocorrência foi extraída de um texto produzido por um terceiro sujeito. Em sua produção, no dia 21 de março de 2002:

o pesquisador solicitou às crianças que escrevessem a letra de sua música preferida. Salientou, várias vezes, que as crianças poderiam escrever quantas músicas quisessem e, também, que poderiam selecionar quaisquer músicas (músicas aprendidas na escola, músicas aprendidas em casa, músicas religiosas etc.) (id., ibid.)

A canção escolhida pela criança foi Cinco patinhos, gravada pela apresentadora de TV Xuxa Meneghel.

\footnotetext{
${ }^{2}$ Alguns desses dados já foram analisados por Serra (2007), em dissertação que a autora desenvolveu sob nossa orientação. Eles terão, porém, tratamento diferente neste estudo.

${ }^{3}$ Por limitação de espaço, não nos ateremos às características desse banco de dados. Uma descrição detalhada de sua constituição e organização pode ser encontrada em Capristano (2007).
} 


\section{Os dados}

Observemos a ocorrência (1):

(1)

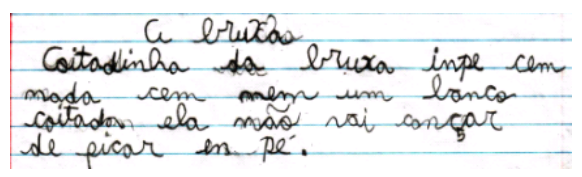

Nesta ocorrência, vê-se, por um lado, a flutuação entre a estrutura hipossegmentada inpe e a estrutura com rasura en pé, e, de outro, a flutuação entre duas grafias possíveis para o segundo membro desse par, a saber, en pé (privilegiada) e enpé (descartada, mas sem que o resíduo gráfico da oscilação da criança entre emendar ou separar duas palavras pudesse ser totalmente apagado).

Vários critérios parecem estar subjacentes a essas flutuações. No que se refere à ancoragem da criança em aspectos prosódicos característicos de sua constituição como falante em práticas de oralidade, na flutuação entre inpe e en pé, detecta-se, por um lado, em inpe, a emergência de uma frase entonacional ou de um grupo clítico, ou, ainda, de um pé métrico, de acordo com Nespor \& Vogel (1986). Por outro lado, em en pé detecta-se a emergência de duas sílabas.

Com efeito, para Nespor \& Vogel, a frase entonacional corresponde a um contorno entonacional característico, muitas vezes delimitado por pausas. Tem-se, pois, como resultado gráfico desse algoritmo, a estrutura inpe, a qual, numa leitura mais lenta, poderia ser delimitada por pausas em suas duas extremidades (ou por vírgulas, numa escrita mais de acordo com as convenções ortográficas). Porém, outra análise da mesma estrutura poderia levar ao reconhecimento de um constituinte prosódico bastante característico de textos escritos infantis, dado seu estatuto problemático no Português Brasileiro: o grupo clítico - constituinte que congrega uma palavra fonológica (portanto, provida de acento: - no caso, a palavra "pé"), a qual funciona como "hospedeiro" de um monossílabo desprovido de acento, o clítico prosódico "em". Outra análise possível é detectar, nessa estrutura, um pé rítmico de cabeça (acento) à direita, ou seja, um pé iambo. Como se vê, o modo de olhar para a estrutura define diferentes possibilidades de categorizá-la e, logo, de entender a sua emergência no enunciado escrito da criança. Se enfatizarmos nela exclusivamente suas características rítmicas, sua interpretação será a de um pé iambo. Se a olharmos de acordo com a relação que nela se estabelece entre informações fonológicas e informações morfossintáticas, sua interpretação 
poderá ser a de um grupo clítico (na perspectiva de Nespor \& Vogel, 1986). Se considerarmos, por fim, a proeminência que essa mesma estrutura pode adquirir, em termos prosódicos, numa leitura possível do enunciado Coitadinha da bruxa, em pé, sem nada, sem um banco, coitada!, ou, em outros termos, se considerarmos o funcionamento dessa estrutura no enunciado como um todo, sua interpretação poderá ser a de uma frase entonacional.

Se, no primeiro elemento do par em flutuação, diferentes constituintes parecem ancorar a escrita da criança, ou seja, critérios conflitantes [atuariam] de forma mais ou menos simultânea (Abaurre, 1991: 205), no segundo elemento apenas um constituinte parece ancorá-la: a sílaba. Assim, o que, num primeiro momento se destaca por seu caráter de aglutinação prosódica (inpe), noutro momento se destaca justamente pela fragmentação da estrutura aglutinada em seus elementos prosódicos mínimos: as sílabas en e pé. É essa alternância, aliás, que parece estar na base das duas maneiras com que a língua se apresenta à criança (uma única unidade ou duas unidades?), indiciada - pelo resíduo de apagamento - por seu conflito entre unir ou separar unidades gráficas.

Mas a flutuação entre inpe e en pé parece ter como ancoragem não apenas diferentes aspectos prosódicos da língua. Conforme antecipamos, pode-se, ainda, pensar que a flutuação se dá como produto da ancoragem da criança - também - em aspectos das convenções ortográficas da língua. Assim, se, por um lado, a criança deixa, em sua escrita, pistas de sua inserção em práticas de oralidade, já que deixa traços de sua ancoragem em características prosódicas da língua (como acabamos de observar), por outro lado, deixa, ainda, em sua escrita, traços de sua inserção em práticas de letramento, já que dá mostras também de sua ancoragem em características das convenções ortográficas. Traços mais nítidos desse segundo tipo de ancoragem se detectam em en pé: por exemplo, o espaço em branco que delimita duas palavras ortográficas da língua ("em" e "pé"); a presença do grafema "e" na palavra "em", registro ortográfico de uma vogal que, na variedade linguística da criança, é pronunciada preferencialmente como [i]; e, ainda, a presença do acento agudo na palavra pé. Traços menos nítidos desse segundo tipo de inserção da criança se detectam em inpe. Mesmo assim, em alguma medida, se deixam entrever, já que os limites inicial e final dessa estrutura correspondem a limites de palavras ortográficas e, ainda, os grafemas correspondem a possibilidades ortográficas para os fonemas da estrutura - índices, portanto, da inserção da criança em práticas de letramento.

Passemos à ocorrência 02: 
(2)

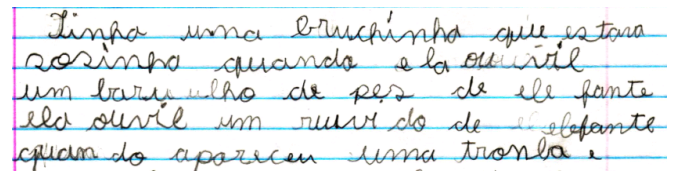

Nessa ocorrência, podem ser detectados três pares de flutuações: (a) a estrutura hipersegmentada e la e a estrutura ela; (b) a estrutura hipersegmentada ou vil e a estrutura ouvil; e, por fim, (c) a estrutura hipersegmentada ele fante e a estrutura elefante.

Nos pares (a) e (b), em termos prosódicos, pode-se detectar a ancoragem da criança em mais de um constituinte prosódico. A separação de unidades, como vimos na ocorrência 01, remete, uma vez mais, à ancoragem no constituinte basilar da hierarquia prosódica proposta por Nespor \& Vogel (1986): a sílaba. Já sua junção remete a mais de um constituinte. Estruturalmente, de início, ao pé métrico - na medida em que ela corresponde a uma unidade rítmica de cabeça (acento) à esquerda, ou seja, a um pé troqueu, e ouvil (bem como a rasura em ou vil), a uma unidade rítmica de cabeça à direita, um pé iambo. Mas a junção remete, estruturalmente, também à palavra fonológica, unidade prosódica, em ambos os casos, de extensão igual à das palavras morfológicas ela e ouviu e necessariamente provida de acento primário. Pensando-se, no entanto, na proeminência que essas duas estruturas podem adquirir no enunciado como um todo, a junção remeteria à frase fonológica, já que, para Nespor \& Vogel (1986), substantivos, verbos, adjetivos, advérbios e alguns pronomes (os que recebem acento) funcionam como unidades prosódicas mais altas, na medida em que, na constituição dessas unidades, interagem informações de natureza fonológica, morfológica e sintática. Vê-se, uma vez mais, que o modo como se olha para as estruturas define a maneira como elas podem ser categorizadas.

Com relação ao par ele fante e elefante, a flutuação parece ancorar-se, mais especialmente, em dois tipos de constituintes prosódicos. A separação sustenta-se numa sequência de dois pés troqueus, ele e fante; já a junção (com ou sem rasura), em uma palavra fonológica (elefante) de extensão igual à da palavra morfológica correspondente. Esse tipo de separação é bastante frequente na escrita infantil e, para ele, Abaurre (1991: 209) fez a seguinte explicação: (...) as crianças, nessa fase, sentem-se particularmente à vontade, em termos rítmicos, com as seqüências em que se alternam regularmente as sílabas fortes e as fracas, nos troqueus binários.

Mas ainda, segundo Abaurre, é razoável supor que a criança atribua, no momento da flutuação, significados conhecidos a partes do enunciado (id, ibid.), como, em nosso caso, a ele, ou também segmente de acordo com formas 
canônicas das palavras no português, como, em nosso caso, fante (e, mesmo, ele), estruturas que respondem à preferência do português, sobretudo no léxico infantil, por dissílabos paroxítonos. Trata-se de estruturas que Cunha (2004: 62-63) considera como palavras fonológicas, na medida em que abarcam a palavra lexical (que possui significado) e [vão] mais além, compreendendo todas as palavras [escritas] que possuem um acento primário e que, embora não tenham significado conhecido na língua, são candidatas potenciais para tal.

Mais uma vez, portanto, em ele fante e elefante, estamos às voltas com flutuações que envolvem não só aspectos prosódicos da língua, como também aspectos lexicais e ortográficos de seu modo de enunciação escrito. Com efeito, a atribuição de sentidos conhecidos a partes de enunciados na escrita parece supor a ancoragem da criança em unidades lexicais da língua com as quais convive nas práticas orais-faladas e letradas-escritas de que participa - e que possibilitam sua constituição como sujeito escrevente. Raciocínio análogo pode ser feito, também, a propósito das flutuações e la / ela e ou vil / ouvil: tanto as separações, quanto as junções, em alguma medida correspondem a palavras (isoladas por espaços em branco na escrita) que a criança provavelmente já tenha lido (e escrito), além de, obviamente, tê-las ouvido (e falado).

Passemos, finalmente, à ocorrência 03:

(3)

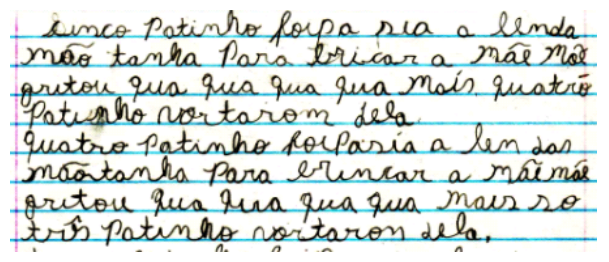

Nessa ocorrência, destacaremos dois pares de flutuação: foipa sia / foipasia e a lenda mão tanha/ a len das mãotanha. Diferentemente dos pares destacados nas ocorrências (1) e (2), nos quais, claramente, tínhamos hipo (inpe) ou hiper ( e la, ou vil, ele fante) segmentação, nos pares da ocorrência (3), além de hipo (foipasia) e hiper ( mão tanha e a len) segmentação, temos o que vimos chamando de mesclas, na medida em que, numa mesma estrutura, detectamse, simultaneamente momentos de hipo e momentos de hipersegmentação (cf. Chacon, 2004, 2005 e 2006). É o que verificamos, por exemplo, em foipa sia e em a lenda. No primeiro caso, a criança agrega à palavra "foi" uma sílaba da palavra seguinte, "pa", de "passear", processo que resulta em um momento de hipo (foipa) e em um momento de hiper (sia) segmentação . No segundo caso, a criança, por um lado, recorta a sílaba "a" (de "além") e, por outro lado, 
agrega ao "lém" restante a palavra "da", processo que resulta num momento de hiper $(a)$ e num momento de hipo (lenda) segmentação.

Nessas mesclas, mais uma vez parecem estar em questão a atuação simultânea (sobre a criança) de critérios conflitantes. Vejamos quais.

No que se refere a aspectos prosódicos, no par foipa sia / foipasia, o conflito que nos parece mais proeminente é aquele entre a frase fonológica e o pé. A junção entre "foi" e "pa" remete a um amálgama que, logo a seguir, é desfeito pelo espaço em branco, mas não sem deixar aflorar a possibilidade de um reconhecimento, por parte da criança, de algo que recobrisse "foi" e "passear". Esse algo, em termos prosódicos, corresponde a uma frase fonológica, na medida em que esse constituinte congrega um elemento que pode funcionar como "cabeça lexical" (preferencialmente um substantivo, um verbo, um adjetivo e um advérbio) e tudo quanto possa ser-lhe acrescido do lado nãorecursivo da língua (o lado esquerdo, no Português Brasileiro) num limite sintático. Exemplificando: o elemento que funciona como "cabeça lexical" no par acima é o verbo (principal) "passear". O verbo "foi", nesse contexto, à esquerda e prosodicamente apoiado em "passear" completa a frase fonológica. Argumento a favor dessa análise é o segundo elemento do par, foipasia, no qual a junção apenas esboçada no primeiro elemento (foipa sia) é concretizada.

Mas apenas a sugestão de uma frase fonológica (indiciada pela junção entre "foi" e "pa") estaria em questão nessa estrutura mesclada? A nosso ver, ao mesmo tempo em que o amálgama indicia um constituinte maior (a frase fonológica), o espaço em branco indicia um constituinte menor. Assim, as duas partes do primeiro elemento do par em análise (foipa e sia), separadas por espaço em branco, correspondem, ritmicamente, a um pé iambo em sia (logo, com acento na sílaba mais à direita) e a um pé troqueu em foipa (ou seja, com acento na sílaba mais à esquerda). Observe-se, porém, que, embora foipa isoladamente corresponda a um pé troqueu, por razões de ordem musical, como veremos a seguir, esse pé será (re)interpretado como iambo.

Marcas da inserção da criança em práticas letradas se apresentariam, também, nessa estrutura mesclada. Mais especificamente, o fato de que os espaços em branco que limitam e se interpõem na estrutura em nenhum momento romperam a sílaba ortográfica (nenhuma consoante foi isolada da vogal que com ela forma sílaba). Também o fato de que os dois limites coincidem com limites de palavras ortográficas indiciam a inserção da criança em práticas de letramento.

Outro fator, no entanto, parece levar à escansão feita pela criança: o musical. Conforme antecipamos, de acordo com a proposta de produção textual, as crianças deveriam escrever a letra de uma canção de que gostassem. A segmentação do primeiro elemento da flutuação em questão responde 
(ortograficamente) à organização rítmica com que a apresentadora Xuxa canta, na gravação da canção, o final do primeiro verso do texto - com maior volume nas sílabas pa e á ("foi PAS-se-AR") ${ }^{4}$. Fato que reforça essa nossa interpretação é o de que, no final do verso seguinte, em que ocorre rima, a apresentadora repete a mesma estrutura rítmica (mudando, inclusive, a estrutura rítmica da palavra), enfatizando as sílabas ra e cá (resultando em "paRA brinCAR). A estrutura rítmica de foipa sia, portanto, é uma estrutura não apenas enfatizada no modo como a apresentadora a canta, como também repetida pela ação da rima.

Vê-se, pois, que a flutuação da criança entre separar e unir palavras remete a um conjunto de fatores (ou de critérios conflitantes, como diz Abaurre): prosódicos, ortográficos e musicais ${ }^{5}$, cuja atuação se dá de modo não repetido e, consequentemente, como pesos diferentes em cada elemento do par. Provavelmente, no primeiro elemento, o critério musical seja o mais saliente; no segundo, o critério prosódico - mas sem que se desconsidere a ação dos restantes. De qualquer modo, tanto a história de fala, quanto a de escrita e, ainda, a de referências de canções da criança comportam elementos que (em graus e pesos difíceis de quantificar e avaliar) determinam sua segmentação.

Talvez o critério musical não seja o mais saliente para a mesma criança em sua flutuação entre a lenda mão tanha / a len das mãotanha. O prosódico e o ortográfico, a nosso ver, se destacam. Mais uma vez, a junção entre "len" (de "além") e "da" remete a alguma forma de reconhecimento de um elemento prosódico mais alto que favoreceria o amálgama. Mais uma vez, pelas mesmas razões expostas na discussão do par anterior, trata-se de uma frase fonológica - com a diferença de que, neste último par, o elemento que funciona como cabeça lexical é o substantivo "montanha", ao qual sintaticamente se agregam (e prosodicamente se apóiam) os elementos à esquerda "além" e "da". Fatos bastante curiosos ocorrem no interior dessa estrutura que poderíamos entender como a sugestão de uma frase fonológica. Em seu interior, emergem pés troqueus binários (acento à esquerda) como "lenda" e "tanha". Sílabas também são isoladas por espaços em branco: "a", "mão", "len" e "das". Uma palavra

\footnotetext{
${ }^{4}$ Xuxa, de fato, pronuncia "foram passiá". A alteração de "foram" para "foi" é feita pela criança. De qualquer modo, essa alteração não afeta os acentos "pa" e "a".

${ }^{5}$ A propósito de segmentações de crianças para a canção tradicional Pirulito que bate, bate, Silva (2005) observa que, no momento em que uma das crianças escreveu o texto, (...) o aspecto rítmico dos versos adquiriu saliência para a criança, conduzindo sua proposta de segmentação (op. cit., p. 240).
} 
fonológica (que corresponde a uma palavra morfológica) também é destacada: "montanha".

Novamente aqui, um provável reconhecimento de unidades lexicais da língua (em sua modalidade de enunciação escrita), providas, ou não de acento, explicaria, sobretudo, as separações para mais (as hipersegmentações). Teríamos, pois, explicadas dessa maneira a emergência de "a" (monossílabo não-acentuado), de "mão" (monossílabo acentuado) e de "lenda" (dissílabo paroxítono). Quanto a "tanha", mais uma vez teríamos a emergência de uma "palavra canônica", ou seja, de um dissílabo paroxítono, de acordo com Abaurre (1991), ou de uma palavra de acento primário [sem] significado conhecido na língua, de acordo com Cunha (2004). Já quanto a "len", possivelmente o reconhecimento, por parte da criança, de "a" e de "das" como palavras ortográficas a tenha levado a isolá-las, provocando, em decorrência desse isolamento, a emergência de "len" entre espaços em branco.

Reforçando Abaure (1991), o mais significativo, a nosso ver, nos possíveis e conflitantes critérios de segmentação subjacentes à flutuação na escrita de uma mesma estrutura é justamente sua convivência e sua ação pontual, local. E é com palavras ainda provisórias ${ }^{6}$ sobre essa convivência e sobre essa oscilação, tão presentes na constituição da criança como escrevente, que encerraremos as considerações feitas neste trabalho.

\section{Movimentos}

As flutuações na segmentação de palavras seriam marcas ${ }^{7}$ da heterogeneidade constitutiva da escrita (Correa, 2001 e 2004) que, de modo mais explícito do que a do adulto, caracteriza a escrita infantil. Em outra perspectiva, seriam marcas, também, de mudanças de posição da criança (De Lemos, 2002) no decorrer de sua constituição como sujeito escrevente.

Voltemos às flutuações ela / lla (ocorrência 02), bem como forpa sea / porparia e a lenda mas tanka / a len das moatanla (ocorrência 03). Para fazer essa volta, inspiramo-nos particularmente em Capristano (2007).

Semelhantemente ao que ocorre na fala infantil, também nessas flutuações de grafia é possível detectar o que, de acordo com de Lemos (2002), poderia

\footnotetext{
${ }^{6}$ Palavras provisórias porque, até o presente momento, não provêm de reflexões que vimos desenvolvendo de modo mais sistemático sobre como a criança se constitui como escrevente.

${ }^{7}$ No sentido atribuído a esse termo por Authier-Revuz (1990).
} 
ser caracterizado como fragmentos de enunciados escritos submetidos ao movimento da língua. Com efeito, uma característica fundamental desse movimento seria a emergência [em nosso caso, na enunciação escrita] de desajustes em relação às convenções ortográficas que indiciariam o nãoreconhecimento, pela criança, da diferença entre sua [escrita] e a [escrita] do outro (De Lemos, 2002: 55), ou mesmo, o não reconhecimento, pela criança, da diferença que caracteriza a sua própria escrita. Evidência desse nãoreconhecimento é que, num mesmo enunciado, tanto ocorre uma escrita fora das convenções quanto uma escrita de acordo com as convenções - o que não autoriza, portanto, o analista da escrita a supor, nos momentos de acordo, um conhecimento das convenções por parte da criança. Ainda outra evidência desse não-reconhecimento nas ocorrências em destaque seria a ausência de rasuras, apagamentos etc. - fato que aponta para uma provável ausência de distanciamento da criança em relação a sua escrita e que a mostra no intervalo entre os significantes que metaforicamente se substituem (...) no erro (id., p. $61)$.

Situação diferente ocorre nas flutuações inpe / en pé (ocorrência 01), bem como nas flutuações
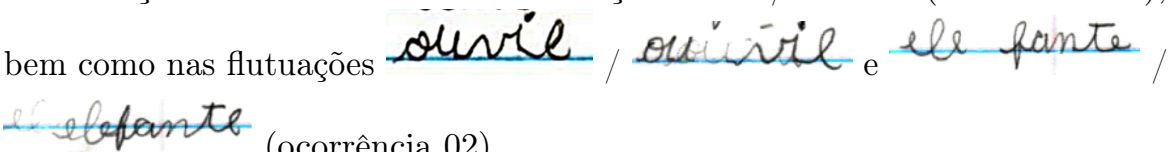

(ocorrência 02).

Em pelo menos um dos elementos desses pares, detectam-se marcas de correção/apagamento. Trata-se, numa adaptação de de Lemos (2002) para nossos propósitos, (...) do reconhecimento do efeito que a substituição pode ter para a própria criança e para seu interlocutor (op. cit., p. 62). Destaque-se que fenômenos equivalentes a estes na fala, como, por exemplo, pausas, reformulações e correções, não são previsíveis, como a noção de metaconhecimento, ou mesmo monitoração da fala, o exigiria (id., ibid.). $\mathrm{O}$ sujeito escrevente, nesse movimento, emergiria, então, num outro intervalo: naquele que se abre entre a instância que fala [escreve] e a instância que escuta [lê], instâncias não coincidentes (id. ibid.).

Assim, essas marcas de correção apontam para uma busca de ancoragem da escrita. E, na mostra dessa busca, apontam para perspectivas de ancoragem não necessariamente coincidentes entre si - uma vez que, como procuramos demonstrar, as marcas de correção sugerem a ancoragem da criança em diferentes instâncias de sua constituição como sujeito escrevente, instâncias que decorrem de uma escrita/fala e de uma leitura/audição que são recuperadas no próprio ato de escrita e deixam pistas em seu produto final. 


\section{Referências bibliográficas}

ABAURRE, Maria Bernadete Marques. Lingüística e psicopedagogia. 1987. In: SCOZ, B.J.L. et al. (org.) Psicopedagogia: O caráter interdisciplinar na formação e atuação profissional. Porto Alegre: Artes Médicas.186-216.

ABAURRE, Maria Bernadete Marques. 1991. A relevância dos critérios prosódicos e semânticos na elaboração de hipóteses sobre segmentação na escrita inicial. Boletim da Abralin 11. 203-17.

AUTHIER-REVUZ, Jacqueline. (1990) Heterogeneidade (s) enunciativa (s). Cadernos de Estudos Lingüisticos. Campinas 19. 25-42.

CAPRISTANO, Cristiane Carneiro. 2007. Mudanças na trajetória da criança em direção à palavra. Campinas. Tese (Doutorado em Linguística Aplicada) - Instituto de Estudos da Linguagem, Unicamp.

CHACON, Lourenço. 2004. Constituintes prosódicos e letramento em segmentações nãoconvencionais. Letras de Hoje 39. 223-32.

CHACON, Lourenço. Hipersegmentações na escrita infantil: entrelaçamento de práticas de oralidade e de letramento. 2005. Estudos Lingüisticos 34. $77-86$.

CHACON, Lourenço. Prosódia e letramento em hipersegmentações: reflexões sobre a aquisição da noção de palavra. 2006. In: CORRÊA, Manoel Luiz Gonçalves. (org.) Ensino de língua: representação e letramento. Campinas: Mercado de Letras. 155-67

CORRÊA, Manoel Luiz Gonçalves. Letramento e heterogeneidade da escrita no ensino de português. 2001. In: SIGNORINI, Inês. (Org.) Investigando a relação oral /escrito e as teorias do letramento. Campinas: Mercado de Letras. 135-166.

CORRÊA, Manoel Luiz Gonçalves. O modo heterogêneo de constituição da escrita. São Paulo: Martins Fontes, 2004.

CUNHA, Ana Paula Nobre A hipo e a hipersegmentação nos dados de aquisição da escrita: um estudo sobre a influência da prosódia. 2004. Pelotas. Dissertação (Mestrado em Educação) - Universidade Federal de Pelotas.

DE LEMOS, Cláudia Thereza Guimarães. (2002) Das vicissitudes da fala da criança e de sua investigação. Cadernos de Estudos Lingüisticos 42. 41-69.

FERREIRA, Carmen Regina Gonçalves. 2010. As hipersegmentações como marcas de um sistema em construção na escrita inicial de crianças e alunos de EJA. In: MARÇALO, Maria João; LIMA-HERNANDES, Maria Célia et ali.. (Org.). Lingua Portuguesa: ultrapassar fronteiras, juntar culturas. Língua Portuguesa: ultrapassar fronteiras, juntar culturas. 01-14. 
NESPOR, Marina \& VOGEL, Irene. Prosodic phonology. 1986. Dordrechet: Foris Publications.

SERRA, Márcia Pereira. Segmentação de palavras: prosódia e convenções ortográficas na elaboração da escrita infantil. 2007. São José do Rio Preto. Dissertação (Mestrado em Estudos Lingüísticos) - Instituto de Biociências, Letras e Ciências Exatas, Unesp.

SILVA, Ademar. Músicas infantis e a representação que a criança faz da linguagem/escrita. 2005. Educação \& Linguagem 11. 232-44.

TENANI, Luciani Ester. 2004. Segmentações não-convencionais e teorias fonológicas. Letras de Hoje 39. 233-44.

TFOUNI, Leda Verdiani. 2000. Letramento e alfabetização. 3.ed. São Paulo: Cortez.

Recebido em: 12/11/2012

Aceito em: 13/02/2013 
